\title{
New examples of specific-base catalysis in mononuclear rearrangements of heterocycles found via a designed modification of the side-chain structure
}

\author{
Francesca D'Anna, ${ }^{a}$ Vincenzo Frenna, ${ }^{a}$ Susanna Guernelli, ${ }^{b}$ Camilla Zaira Lanza, \\ Gabriella Macaluso, ${ }^{a}$ Salvatore Marullo, ${ }^{a}$ and Domenico Spinelli ${ }^{b}$ \\ ${ }^{a}$ Dipartimento di Chimica Organica 'E. Paternò', Università di Palermo, Viale delle Scienze, \\ Parco d'Orleans 2, 90128 Palermo, Italy, 'Dipartimento di Chimica Organica 'A. Mangini', \\ Università di Bologna, Via San Giacomo 11, 40126 Bologna, Italy \\ E mail: domenico.spinelli@unibo.it
}

\begin{abstract}
Dedicated to Professor Nicolò Vivona on the occasion of his $70^{\text {th }}$ birthday, remembering his contributions to the study of the interconversion of azoles
\end{abstract}

\begin{abstract}
To select suitable candidates for the occurrence of specific-base-catalysis in MRH of (Z)-hydrazones of 3-benzoyl-5-phenyl-1,2,4-oxadiazole we have designed a modification of the side-chain structure by linking a strong electron-withdrawing system to the hydrazono group. Thus we have synthesized the (Z)-semicarbazone (3d), the (Z)-phenylsemicarbazone (3e), and the $(Z)$-acetylhydrazone (3f) of the above oxadiazole and examined their kinetic behavior in dioxane/water in a large range of proton concentrations $\left(\mathrm{p} S^{+} 4.0-14.5\right)$. In all the $\mathrm{p} S^{+}$range examined only a base-catalyzed process has been evidenced (no uncatalysed path occurs). The behavior at the largest $\mathrm{pS}^{+}$values (the reactivity tends to a limiting rate constant) and that at variable concentrations of buffer have furnished clear evidence for the occurrence of a specificbase-catalysed process, thus reaching the target proposed and confirming the prevision.
\end{abstract}

Keywords: Monocyclic rearrangements of heterocycles, specific-base-catalysis in dioxane/water, general-base-catalysis in toluene, side chain structure effect

\section{Introduction}

The study of the synthesis and of the reactivity of heterocyclic compounds is actually one of the main subjects of organic chemists, sometimes for pure scientific interest but also for the large use of heterocyclic derivatives as synthones or as masked functionalities ${ }^{1}$ as well as in practical applications (from medicinal chemistry to materials industry). ${ }^{2}$ Sometimes the synthetic aspects 
concerning the preparation of heterocyclic compounds can be difficult to solve, also if a lot of different methods and of new synthetic strategies are continuously proposed. ${ }^{3}$

Together with already known classical transformation reactions of functional groups, that are useful in the synthesis of heterocyclic compounds having one or more heteroatoms, ${ }^{4}$ and together with the cycloaddition, ${ }^{3}$ phototransformations, ${ }^{3}$ and ANRORC $^{5}$ reactions that often allow to synthesize structurally very complex compounds, also mononuclear rearrangement of heterocycles $\left(\mathrm{MRH}^{6}{ }^{6}\right.$ see Scheme 1) can be a valid synthetic approach to obtain heterocyclic compounds containing at least one nitrogen atom in the ring.

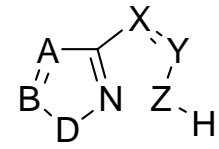

1

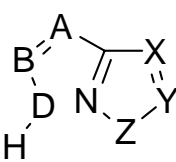

2

\section{Scheme 1}

MRH (as pointed out by us and by other Authors, ${ }^{6 c,-\mathrm{f} g}$ the rearrangement easily occurs only when in $1 \mathrm{D}=\mathrm{O}$ ), recognised in the sixties by Boulton and Katritzky ${ }^{6 \mathrm{a}}$ as a reaction of general synthetic validity, has been widely studied both from a mechanistic ${ }^{7}$ (by collecting kinetic as well as computational data) and a synthetic point of view, ${ }^{6 \mathrm{~b}-\mathrm{g}}$ looking with special attention to the stability of starting and final products as a function of their aromaticity and of their overall structure. $^{8}$

As a matter of fact this approach appears able to identify the whole of the factors affecting the course of MRH, and then can furnish the logical instruments to achieve the appropriate methodologies useful to obtain the target molecules, thus reaching the synthetic goal.

In this line, we have recently carried out a combined kinetic and computational study of the rearrangement of the (Z)-hydrazones of 3-benzoyl-5-phenyl-1,2,4-oxadiazole (3a) and of 3formyl-1,2,4-oxadiazole (5), ${ }^{7 \mathrm{j}}$ respectively.

Moreover the kinetic data collected by examining the reactivity of $\mathbf{3 a} \mathbf{a}^{7 \mathrm{j}}$ and $\mathbf{3} \mathbf{b}^{7 \mathrm{a}}$ have pointed out that, as several other $(Z)$-arylhydrazones previously investigated, ${ }^{7 \mathrm{~d}, \mathrm{~d}}$ they rearrange in dioxane/water $(\mathrm{D} / \mathrm{W} ; 1: 1, \mathrm{v} / \mathrm{v})$ in the $\mathrm{p} S^{+}\left(\mathrm{p} S^{+}\right.$represents an operational proton concentration scale characteristic of the mixed solvent used, see in Experimental under $\mathrm{pS}^{+}$scale definition and kinetic measurements) range 5.55-13.9 into the relevant triazoles (4a) and (4b) following two different kinds of reaction channels (see Figure 1 and Scheme 2): a proton-concentrationindependent pathway (uncatalyzed pathway) and a proton-concentration-dependent one (basecatalyzed pathway). ${ }^{7 \mathrm{c}}$ 
<smiles>IN/N=C(/c1ccccc1)c1noc(-c2ccccc2)n1</smiles>

3

$$
\begin{aligned}
& \text { a: } \mathrm{J}=\mathrm{H} \\
& \text { b: } \mathrm{J}=\mathrm{C}_{6} \mathrm{H}_{5} \\
& \text { c: } \mathrm{J}=\mathrm{C}_{6} \mathrm{H}_{3}\left(o, p-\mathrm{NO}_{2}\right)_{2} \\
& \text { d: } \mathrm{J}=\mathrm{CONH}_{2} \\
& \text { e: } \mathrm{J}=\mathrm{CONHC}_{6} \mathrm{H}_{5} \\
& \text { f: } \mathrm{J}=\mathrm{COCH}_{3}
\end{aligned}
$$

\section{Scheme 2}

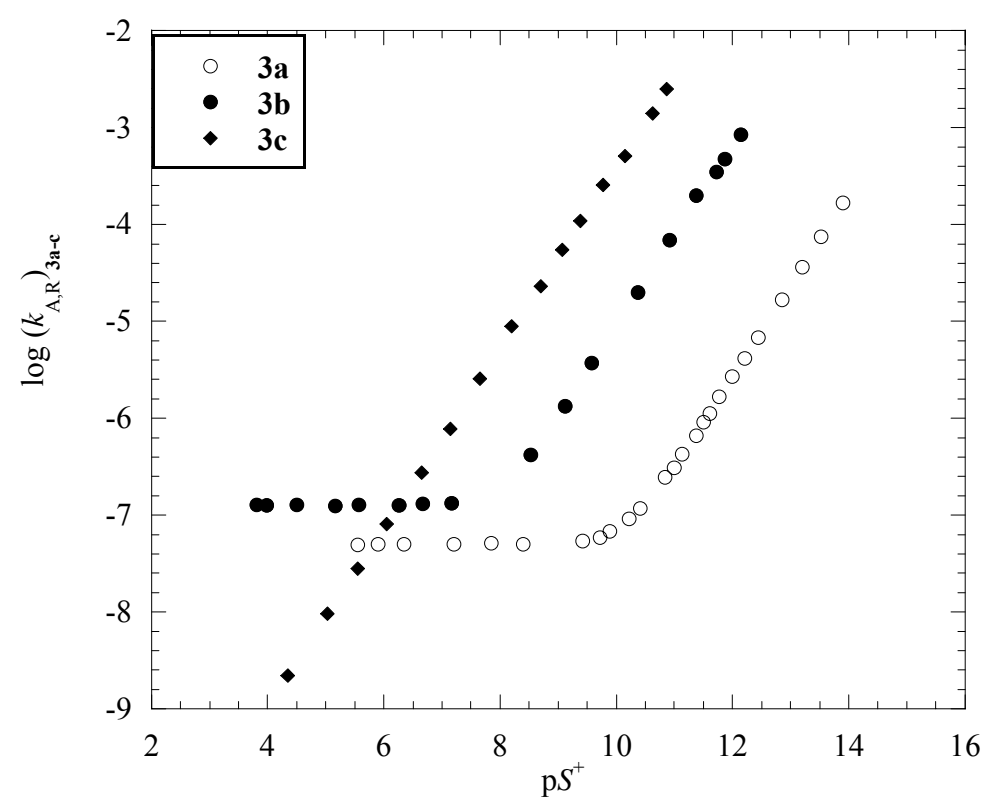

Figure 1. Plot of $\log \left(k_{\mathrm{A}, \mathrm{R}}\right)_{\mathbf{3} \mathbf{a}-\mathbf{c}}$ for the rearrangement of $\mathbf{3 a} \mathbf{a}-\mathbf{c}$ into the relevant triazoles $\mathbf{4 a}-\mathbf{c}$ at $293.1 \mathrm{~K}$ in $\mathrm{D} / \mathrm{W}(1: 1, \mathrm{v}: \mathrm{v})$ versus $\mathrm{p} S^{+}$.

The very nature of the second pathway (via a general- or a specific-base-catalysis) ${ }^{9}$ has been deeply investigated by studying the rearrangement in the $\mathrm{pS}^{+}$range $10.8-12.5$ at different buffer concentration observing an increase of the rate constants with the buffer concentration. ${ }^{7 \mathrm{c}}$ This result suggests for the base-catalyzed pathway the formation of a van't Hoff complex (its formation depends on the concentration of every present base) and then the occurrence of a general-base-catalysis, ${ }^{7 c, 9}$ thus replicating the situation "usually" observed in several (Z)arylhydrazones (in 1, side chain $-\mathrm{X}=\mathrm{Y}-\mathrm{ZH}=>\mathrm{C}=\mathrm{N}-\mathrm{NH}-\mathrm{Ar}$ ) whatever was the substituent present in the aryl. ${ }^{7 \mathrm{~b}, \mathrm{~d}}$ 
Moreover also in the case of the rearrangement of the (Z)-2,4-dinitrophenylhydrazone of 3benzoyl-5-phenyl-1,2,4-oxadiazole $(3 \mathbf{c})^{7 \mathrm{~g}}$ into $4 \mathbf{c}$ (see Figure 1) a general-base-catalysis was observed. That is, the presence of two strong electron-withdrawing nitro groups in conjugated positions with respect to the hydrazono moiety, and then able to increase the acidity of the $\mathrm{N}_{\alpha}-\underline{\mathrm{H}}$ proton, anyway appeared unable to achieve the conditions for the occurrence of a specific-basecatalysis. ${ }^{10}$ On the other hand the present nitrogroups strongly lowered the nucleophilic character of $\underline{\mathrm{N}}_{\alpha}$ and then suppressed the uncatalyzed pathway.

Interestingly a study of the substituent effect on the rearrangement of the substituted (Z)-phenylhydrazones of 3-benzoyl-5-phenyl-1,2,4-oxadiazole into the relevant triazoles, in the general-base-catalyzed range in $\mathrm{D} / \mathrm{W}$ by using the free energy relationship approach, evidenced ${ }^{7 \mathrm{~d}}$ that the very nature of the transition state pertinent to the rate-determining step can vary with the nature of the present substituent. As a matter of fact it appeared clear that, depending on the electronic effects of the present substituent two different situations can be achieved: $a$ ) the nucleophilicity of $\underline{N}_{\alpha}$ atom or $b$ ) the acidity of $\mathrm{N}_{\alpha}-\underline{H}$ proton could represent alternatively the main factor in determining the structure of the rate-determining transition state (r.d.t.s.) and then the rate of reaction.

Also the theoretical study of the uncatalyzed pathway of the rearrangement of the $(Z)$ hydrazone of 3-formyl-1,2,4-oxadiazole (5) into the relevant 4-formylamino-2H-1,2,3-triazole (6) (Scheme 3) has been examined ${ }^{7 \mathrm{j}}$ at the DFT level ${ }^{11}$ in gas phase as well as in the presence of water molecules and also considering the environmental effect of the solvent (by using a COSMO approach). ${ }^{12}$ We observed that by involving two water molecules (able to behave as general bases and as proton shuttles) and considering the polar solvent effect the results of computations suggest that the preferred path is concerted and asynchronous, that is the nucleophilic attack of the hydrazonic nitrogen $\left(\underline{N}_{\alpha}\right)$ onto oxadiazolic $\underline{N}-2$ and the proton transfer from the hydrazonic nitrogen occur in the same kinetic step, but not simultaneously. ${ }^{7 \mathrm{j}}$

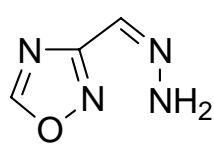

5

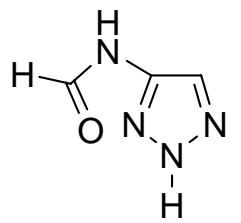

6

\section{Scheme 3}

Interestingly enough the kinetic study of the rearrangement in $\mathrm{D} / \mathrm{W}$ at different proton concentrations of the 3-phenylureine of the 5-phenyl-1,2,4-oxadiazole ${ }^{7 \mathrm{e}}$ (7) and of the $\mathrm{N}$-(5phenyl-1,2,4-oxadiazol-3-yl)- $N^{\prime}$-phenylformammidine ${ }^{7 \mathrm{f}}(\mathbf{8})$ into the relevant $1 H$-1,2,4-triazolin5-ones (9) and $1 \mathrm{H}$-1,2,4-triazoles (10) has shown that the base-catalyzed pathway occurs via a specific-base-catalysis according with the "high" acidity of the underlined proton of the side chain $^{9,10}$ (in Scheme 1: $-\mathrm{X}=\mathrm{Y}-\mathrm{ZH}=-\mathrm{NH}-\mathrm{CO}-\mathrm{N} \underline{\mathrm{H}}-\mathrm{Ph}$ or $-\mathrm{N}=\mathrm{CH}-\mathrm{N} \underline{\mathrm{H}}-\mathrm{Ph}$, respectively). 


\section{Selection of Suitable Candidates for the Occurrence of Specific-base-catalysis in the MRH Process.}

The above considerations have induced us to address our attention to attempts of modification of the $>\mathrm{C}=\mathrm{N}-\mathrm{N}_{\alpha} \underline{\mathrm{H}}-\mathrm{J}$ side chain with the aim of obtaining substrates in which the underlined hydrogen becomes so acid to give rise with hydroxide ions to an acid-base interaction largely shifted on the right (see Scheme 4).

$$
>\mathrm{C}=\mathrm{N}-\mathrm{N}_{\alpha} \mathrm{H}-\mathrm{J}+\mathrm{OH}^{-} \rightleftharpoons \mathrm{C}=\mathrm{N}-\mathrm{N}_{\alpha}-\mathrm{J}+\mathrm{H}_{2} \mathrm{O}
$$

\section{Scheme 4}

In this framework we have addressed our attention to $(Z)$-hydrazones in which the $\mathrm{J}$ group represents a substituent able to conjugate with the $\mathrm{N}_{\alpha}$ nitrogen atom (see Scheme 5).

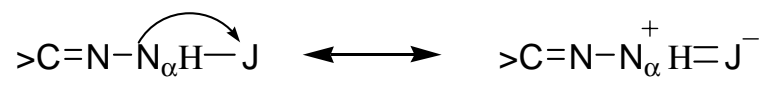

\section{Scheme 5}

The simplest $\mathbf{J}$ group able to shift the above equilibrium towards right seems to us a carbonyl group, thus we have synthesized the $(Z)$-semicarbazone (3d), the $(Z)$-phenylsemicarbazone $(\mathbf{3 e})$, and the (Z)-acetylhydrazone (3f) of 3-benzoyl-5-phenyl-1,2,4-oxadiazole and investigated the kinetic course of their rearrangement into the relevant triazoles $(\mathbf{4 d}-\mathbf{f})$ in $\mathrm{D} / \mathrm{W}$ at different proton concentrations.

In all of the considered compounds a "strong" increase of the acidity of the $\mathrm{N}_{\alpha}-\underline{\mathrm{H}}$ hydrazonic hydrogen would be expected considering the presence of a $>C=O$ group conjugated with the $\mathrm{N}_{\alpha}$ of the $\mathrm{N}_{\alpha}-\underline{\mathrm{H}}$ system (see Scheme 5). This fact could be able to shift the mechanism of the protonconcentration-dependent pathway from a general-base-catalysis towards a specific-base-catalysis also in the instance of a $>\mathrm{C}=\mathrm{N}-\mathrm{NH}-\mathrm{J}$ side chain (see above). At the same time, this factor would also be able to strongly decrease the nucleophilicity of the $N_{\alpha}$ of the $N_{\alpha}-\underline{H}$ system, thus lowering the reactivity in the uncatalyzed pathway or completely preventing its occurrence.

Moreover we have studied these rearrangements in toluene, at $313.15 \mathrm{~K}$, in the presence of some amines with different steric requirements and basicities, that as we have already pointed out could differently affect the course of the reaction. 


\section{Results and Discussion}

\section{Kinetic Study of the Rearrangement of 3d-f in $D / W(1: 1, v: v)$.}

The title rearrangement has been studied in the temperature range $288.1-313.1 \mathrm{~K}$ in the $\mathrm{pS}^{+}$ range 3.9-14.8 (at lower $\mathrm{pS}^{+}$values the rate constants become lower and lower; moreover the acidic hydrolysis of $\mathbf{3 d} \mathbf{d}-\mathbf{f}$ significantly competes with their rearrangement, as already observed studying the behavior of several hydrazones $){ }^{7 \mathrm{a}-\mathrm{g}}$ The apparent-rate-constants $\left[\left(k_{\mathrm{A}, \mathrm{R}}\right)_{\mathbf{3 d}-\mathbf{f}}\right]$ at some $\mathrm{pS}^{+}$values $(5.0,7.0,9.0,11.0$, and 13.0) and at $293.1 \mathrm{~K}$ together with the thermodynamic parameters calculated at 293.1 K are collected in Table 1 (detailed data are in Tables 5-7 of SI).

Table 1. Apparent rate constants, $k_{\mathrm{A}, \mathrm{R}}{ }^{\mathrm{a}}$ at $293.1 \mathrm{~K}$ and activation parameters ${ }^{\mathrm{b}}$ measured at $\mathrm{pS}^{+}$ 5.0, 7.0, 9.0, 11.0, and 13.0 for the rearrangement of $\mathbf{3 d}-\mathbf{f}$ into $\mathbf{4 d}-\mathbf{f}$ in $\mathrm{D} / \mathrm{W}(1: 1, \mathrm{v}: \mathrm{v})$.

\begin{tabular}{cccccc}
\hline Substrate & $\left(k_{\mathrm{A}, \mathrm{R}}\right)_{5.0}$ & $\left(k_{\mathrm{A}, \mathrm{R}}\right)_{7.0}$ & $\left(k_{\mathrm{A}, \mathrm{R}}\right)_{9.0}$ & $\left(k_{\mathrm{A}, \mathrm{R}}\right)_{11.0}$ & $\left(k_{\mathrm{A}, \mathrm{R}}\right)_{13.0}$ \\
& $\Delta \mathrm{H}^{\#}, \Delta \mathrm{S}^{\#}$ & $\Delta \mathrm{H}^{\#}, \Delta \mathrm{S}^{\#}$ & $\Delta \mathrm{H}^{\#}, \Delta \mathrm{S}^{\#}$ & $\Delta \mathrm{H}^{\#}, \Delta \mathrm{S}^{\#}$ & \\
\hline \multirow{2}{*}{ 3d } & $3.48 \cdot 10^{-9}$ & $2.49 \cdot 10^{-7}$ & $1.77 \cdot 10^{-5}$ & $1.27 \cdot 10^{-3}$ & 0.0876 \\
& $99,-53$ & $100,-2$ & $81,-57$ & $81,-23$ & \\
\multirow{3}{*}{ e } & $3.05 \cdot 10^{-8}$ & $2.24 \cdot 10^{-6}$ & $1.65 \cdot 10^{-4}$ & $1.21 \cdot 10^{-2}$ & 0.657 \\
& $99,-53$ & $100,-24$ & $85,-28$ & $83,+2$ & \\
\multirow{3}{*}{ 3f } & $1.96 \cdot 10^{-8}$ & $1.49 \cdot 10^{-6}$ & $1.13 \cdot 10^{-4}$ & $8.63 \cdot 10^{-3}$ & 0.595 \\
& $99,-54$ & $100,-14$ & $83,-35$ & $82,-3$ & \\
\hline
\end{tabular}

${ }^{\mathrm{a}}\left(\mathrm{s}^{-1}\right) .{ }^{\mathrm{b}}\left(\mathrm{kJ} \mathrm{mol}^{-1}, \mathrm{~J} \mathrm{~mol}^{-1} \mathrm{~K}^{-1}\right)$.

In Figure 2 the relevant $\log \left(k_{\mathrm{A}, \mathrm{R}}\right)_{3 \mathbf{d}-\mathbf{f}}$ at $293.1 \mathrm{~K}$ are reported versus the $\mathrm{pS}^{+}$values together with kinetic data concerning the ring-to-ring interconversion of $\mathbf{3 a}$ into $4 \mathbf{a}$. 


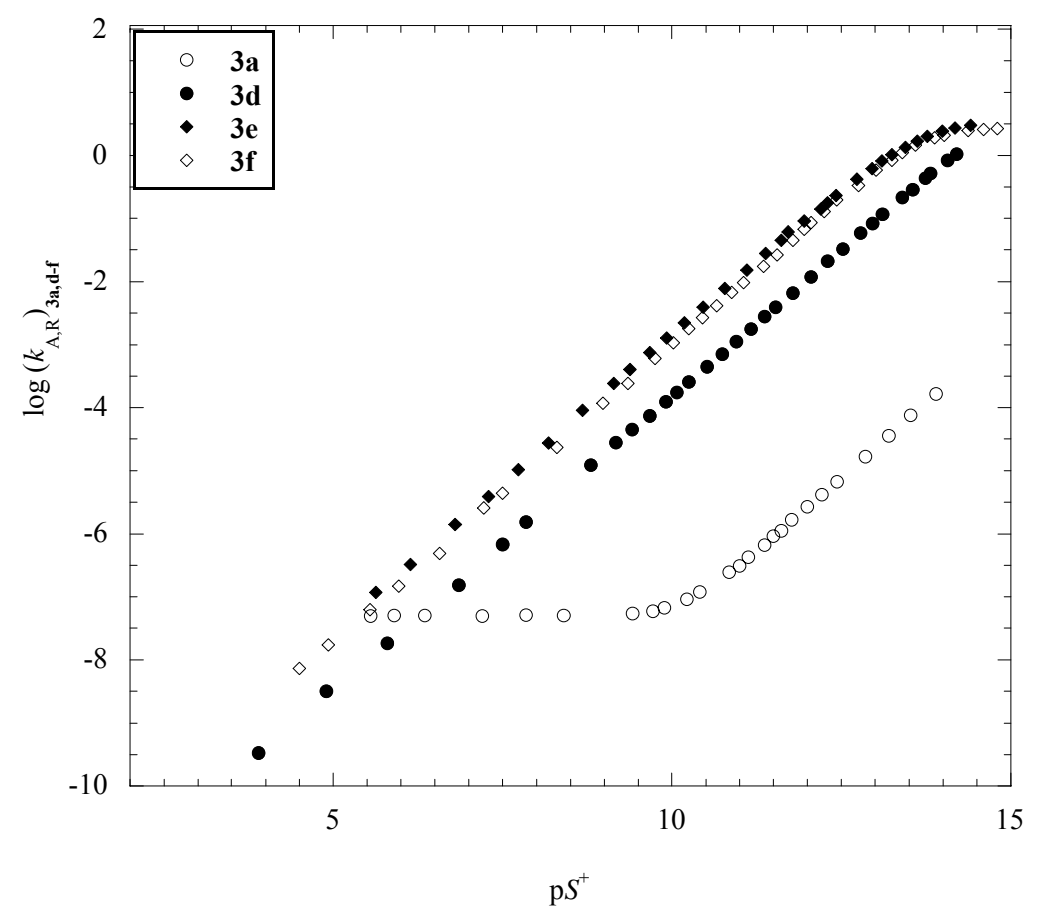

Figure 2. Plot of $\log \left(k_{\mathrm{A}, \mathrm{R}}\right)_{\mathbf{3}, \mathbf{a}-\mathbf{d}-\mathbf{f}}$ for the rearrangement of $\mathbf{3 a , d}-\mathbf{f}$ into the relevant triazoles $4 \mathbf{a}, \mathbf{d}-\mathbf{f}$ at $293.1 \mathrm{~K}$ in $\mathrm{D} / \mathrm{W}(1: 1, \mathrm{v}: \mathrm{v})$ versus $\mathrm{p} S^{+}$.

An examination of Figure 2 evidences for the rearrangement of $\mathbf{3 d}-\mathbf{f}$ a linear increase ${ }^{13}$ of the reaction rates with increasing $\mathrm{pS}^{+}$values up to reach a limiting-rate-constant, at $\mathrm{p} S^{+} \mathrm{ca} .14 .6$ and 14.3 for $\mathbf{3 e}$ and $\mathbf{3 f}$, respectively. In the instance of $\mathbf{3 d}$ only an inflection at the highest $\mathrm{pS}^{+}$, $\mathrm{s}(>14.6)$ could be envisaged. At first sight two other comments can be made:

a) the occurrence of the uncatalyzed pathway could not be evidenced for $\mathbf{3 d}-\mathbf{f}$ according with the very low nucleophilic character for the semicarbazonic or the acetylhydrazonic $\underline{N}_{\alpha}$ nitrogen (for a comparison, look at the different behavior observed in the instances of $\mathbf{3 a}-\mathbf{c}$ : see Figure 1$){ }^{7 \mathrm{a}, \mathrm{g}, \mathrm{j}}$

b) the trend observed for the apparent-rate-constants at high $\mathrm{pS}^{+}$values suggests the formation of an Arrhenius complex (its formation depends only on the concentration of the lyate base) for the base-catalyzed pathway and then the occurrence of a specific-base-catalysis. ${ }^{9}$ This behavior appears in line with the high foreseen acidity of the semicarbazonic or the acetylhydrazonic hydrogens $\left(\mathrm{N}_{\alpha}-\underline{\mathrm{H}}\right)$ of $\mathbf{3 d}-\mathbf{e}$ and $\mathbf{3 f}$, respectively. ${ }^{10}$ To confirm this outcome we have studied the rearrangement of 3d-f in the $\mathrm{pS}^{+}$range 9.8-12.4, 9.7-11.6 and 9.0-11.6, respectively, at different borate buffer concentrations $(0.0125-0.0500 \mathrm{M})$, observing that there is no increase of the $\left(k_{\mathrm{A}, \mathrm{R}}\right)_{\mathbf{3} \mathbf{d}-\mathbf{f}}$ values with buffer concentration at constant $\mathrm{pS}^{+}$(see data in Tables 8-10 of SI). This result indicates that only the bimolecular hydroxide-catalyzed pathway is effective, without any significant contribution by other pathways (bi- or ter-molecular) involving other basic or acidic catalysts.

The above evidence agrees with a reaction mechanism (see Scheme 6) occurring via eq.s 1 and 2, where $\mathrm{SH}$ and $\mathrm{S}^{-}$represent the rearranging substrates and their conjugated bases, 
respectively, and $\mathrm{P}^{-}$the conjugated base of the reaction products. By applying the steady state approximation to the $\mathrm{S}^{-}$intermediate eq. 3 can be obtained.
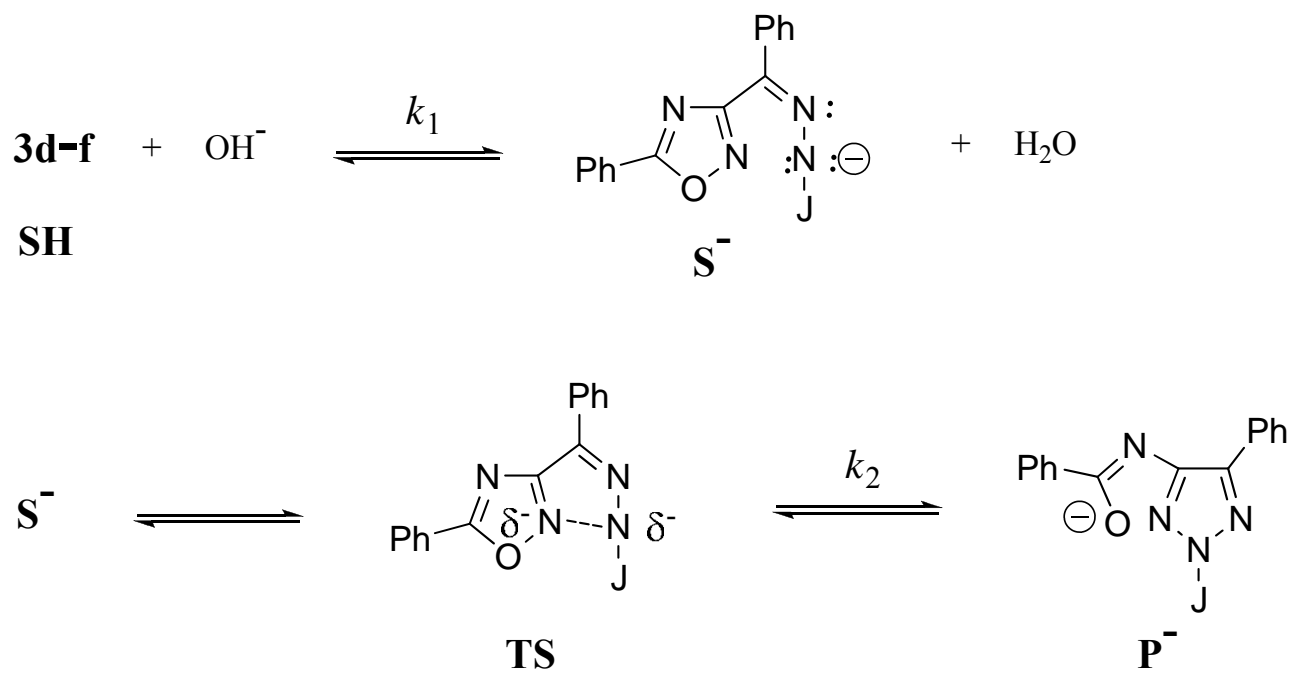

Scheme 6

$$
\begin{array}{ll}
\mathrm{SH}+\mathrm{OH}^{-} \leftrightarrows \mathrm{S}^{-}+\mathrm{H}_{2} \mathrm{O} & \text { eq } 1 \\
\mathrm{~S}^{-} \rightarrow \mathrm{P}^{-} & \text {eq } 2 \\
k_{\mathrm{A}, \mathrm{R}}=\left(K_{1} k_{2}\left[\mathrm{OH}^{-}\right]\right) /\left(1+K_{1}\left[\mathrm{OH}^{-}\right]\right) & \text {eq } 3
\end{array}
$$

Of course at different proton concentrations the two following situations can be envisaged: $1 \gg K_{1}\left[\mathrm{OH}^{-}\right]$or $1 \ll K_{1}\left[\mathrm{OH}^{-}\right]$. Consequently at different $\mathrm{pS}^{+}$values the relevant kinetic expressions deriving from eq. 3 could evolve to eq.s 4 and 5, which describe the kinetic behavior at low and high hydroxide ion concentrations, respectively. As a matter of fact in these two situations the apparent-rate-constants may or may not depend on the hydroxide ion concentrations, as well evidenced in Figure 2 in the instances of $\mathbf{3 e - f}$.

$$
\begin{array}{ll}
k_{\mathrm{A}, \mathrm{R}}=K_{1} k_{2}\left[\mathrm{OH}^{-}\right] & \text {eq. } 4 \\
k_{\mathrm{A}, \mathrm{R}}=k_{2} & \text { eq. } 5
\end{array}
$$

By fitting the $k_{\mathrm{A}, \mathrm{R}}$ values calculated at $293.1 \mathrm{~K}$ from activation parameters to eq. 3 and by using a non-linear least-square-treatment we obtained $K_{1}$ and $k_{2}$ for the three considered substrates with excellent correlation coefficients $(n=32,20$, and 26, respectively; $R>0.9997$, see data in Tables 8-10 of SI). The calculated $K_{1}$ and $k_{2}$ values (data in Table 2) agree with the proposed mechanism: in all the cases we obtained indication in favour of a fast and largely shifted towards right equilibrium (eq. $1 ; K_{1} 7.7-99 \mathrm{~mol}^{-1} \mathrm{~L}$ ) and of a relatively slow rearrangement process (eq. $\left.2 ; k_{2} 2.7-4.0 \mathrm{~s}^{-1}\right)$.

Looking at the calculated $K_{1}$ and $k_{2}$ values $\left[\left(K_{1}\right)_{3 \mathbf{d}}:\left(K_{1}\right)_{3 \mathbf{e}}:\left(K_{1}\right)_{\mathbf{3 f}}=1: 10.4: 12.8\right.$; $\left.\left(k_{2}\right)_{\mathbf{3 d}}:\left(k_{2}\right)_{\mathbf{3} \mathbf{e}}:\left(k_{2}\right)_{\mathbf{3} \mathbf{f}}=1: 0.87: 0.67\right]$ it appears evident that the significantly higher reactivity of $\mathbf{3 e}$ 
and $3 \mathbf{f}$ with respect to $\mathbf{3 d}$ in the $\mathrm{pS}^{+}$-dependent range (where the eq. 4 is operating) is essentially linked to the higher acidity of the $\mathrm{N}_{\alpha}-\underline{\mathrm{H}}$ proton of the $>\mathrm{C}=\mathrm{N}-\mathrm{NH}-\mathrm{J}$ systems now examined, however expected considering the acidifying electronic effect of the present groups: a phenyl instead of an hydrogen in the former case (3e) and an acetyl instead of $\mathrm{CO}-\mathrm{NH}_{2}$ in the latter (3f).

The comparably small differences between the $k_{2}$ values clearly indicate that the most important factor determining the entity of the $k_{2}$ values is its anionic character (which in turn affects its nucleophilicity), that, as expected, exerts a levelling kinetic effect. On the other hand higher acidity means higher stability of the anions, and this, in turn, causes lower nucleophilic character. Perhaps also some effect can be attributed to the different stability of the formed triazoles $(\mathbf{4 d}-\mathbf{f})$ or their anions $\left(\mathbf{4} \mathbf{d}^{-}-\mathbf{f}\right)$ which could in some way affect the position of the r.d.t.s. along the reaction coordinate.

On the whole we can say that the more important factor in determining the global reactivity is the trend of $K_{1}$ values rather than that of $k_{2}$ values.

In the instance of $\mathbf{3 f}$ examining the reactivity at the highest $\mathrm{pS}^{+}$values, where the relevant plot reaches a plateau, accordingly with eq. 5 a comparison between $k_{2}$ values calculated by fitting and experimentally observed is meaningful.

An excellent agreement (Table 2 ) between the two values can be evidenced: $\left(k_{2}\right)_{\text {calc }} 2.66 \mathrm{~s}^{-1}$ and $\left(k_{2}\right)_{\exp } 2.50 \mathrm{~s}^{-1}$. Considering that the experimental rate constants are reproducible within $\pm 3 \%$ and that the $\left(k_{2}\right)_{\text {calc }}$ value is a secondary (that is, re-calculated) value, the difference observed can be well considered in the frame of uncertainty.

In the case of $3 \mathbf{e}$ the plateau is not so sharp, consequently the difference between the calculated and experimental $k_{2}$ values is a little higher, but always in the limits of expectations $\left[\left(k_{2}\right)_{\text {calc }} 3.48 \mathrm{~s}^{-1}\right.$ and $\left.\left(k_{2}\right)_{\exp } 3.00 \mathrm{~s}^{-1}\right]$.

Finally in the instance of $\mathbf{3 d}$, as suggested by an examination of Figure 2, such a comparison is meaningless.

Of course the equilibrium constant $\left(K_{1}\right)$ can be directly obtained from eq. 4 by using $\left(k_{2}\right)_{\exp }$, all the other terms $\left(k_{\mathrm{A}, \mathrm{R}}\right.$ and $\left.\left[\mathrm{OH}^{-}\right]\right)$being known and once more an excellent correspondence between the obtained values has been observed (see data in Table 2).

At last the calculated $K_{1}$ values can be used to obtain the $K_{\mathrm{a}}$ in dioxane/water for $\mathbf{3 d}-\mathbf{f}$ (that is the acid dissociation constants relative to the semicarbazonic or acetylhydrazonic $>\mathrm{N}_{\alpha}-\underline{\mathrm{H}}$ protons of the studied substrates) through eq. 6.

$$
K_{1}=K_{\mathrm{a}} K_{\mathrm{w}} \quad \text { eq. } 6
$$

where $K_{\mathrm{w}}\left(10^{-15.8}\right)$ is the water ionic product in the mixed solvent used. The $\mathrm{p} K_{\mathrm{a}}$ values are reported in Table 2: in agreement with the observed specific-base-catalysis $\mathbf{3 c}-\mathbf{e}$ are acids stronger than water $\left(K_{\mathrm{a}}=5.71 \cdot 10^{-18} \mathrm{~mol} \mathrm{~L}^{-1}\right.$ in $\left.\mathrm{D} / \mathrm{W}\right)$ and, as observed, can easily give the conjugated bases by the action of hydroxide ions.

The whole of the kinetic results suggests for the studied reaction a one-step concerted mechanism with synchronous $\mathrm{N}-\mathrm{N}$ bond-forming and $\mathrm{N}-\mathrm{O}$ bond-breaking as also supported by 
some preliminary calculations at DFT level in gas phase (work in progress). Calculated structures and energy contents for reagents, transition state, and final products are well in line with expectations.

Such an observed result appears of interest especially in comparison with that previously obtained in the study of MRH of 5 into 6 in the uncatalyzed pathway ${ }^{7 j}$ (see above). At the same time, this result enforces the observations concerning the different course of $\mathrm{S}_{\mathrm{N}} 2$ reactions, the substrate being the same, as a function of the nature of the used nucleophile, neutral or anionic, respectively.

Table 2. Equilibrium constants, $K_{1}$, catalyzed rearrangement rate constants, $k_{2}$, calculated according to eq. $3[\mathrm{D} / \mathrm{W}(1: 1, \mathrm{v}: \mathrm{v})$ at $293.1 \mathrm{~K}]$, and $\mathrm{p} K_{\mathrm{a}}$ of acidic $\mathrm{N}_{\alpha}-\underline{\mathrm{H}}$ proton for $\mathbf{3 d}-\mathbf{f}, 7$ and 8.

\begin{tabular}{cccc}
\hline Substrate & $\left(K_{1}\right)_{\text {calc }}\left(\mathrm{mol}^{-1} \mathrm{~L}\right)$ & $\left(k_{2}\right)_{\text {calc }}\left(\mathrm{s}^{-1}\right)^{\mathrm{a}}$ & $\mathrm{p} K_{\mathrm{a}}$ \\
\hline 3d & $7.7 \pm 0.2$ & $4.00 \pm 0.08$ & 14.9 \\
$\mathbf{3 e}$ & $80 \pm 1(86)$ & $3.48 \pm 0.02(3.00)$ & 13.9 \\
$\mathbf{3 f}$ & $99 \pm 2(94)$ & $2.66 \pm 0.03(2.50)$ & 13.8 \\
$\boldsymbol{7}^{\mathrm{b}}$ & $2699 \pm 63$ & $(6.94 \pm 0.03) \cdot 10^{-5}$ & 12.4 \\
$\mathbf{8}^{\mathrm{c}}$ & $52.4 \pm 0.7$ & $(2.69 \pm 0.01) \cdot 10^{-3}$ & 14.1 \\
\hline
\end{tabular}

${ }^{\mathrm{a}}$ In parentheses the experimental $\left(K_{1}\right)_{\exp }$ and $\left(k_{2}\right)_{\exp }$ are reported. ${ }^{\mathrm{b}}$ Data from reference $7 \mathrm{e} .{ }^{\mathrm{c}}$ Data from reference $7 \mathrm{f}$.

\section{A Comparison between the Reactivity of 3d-3f and 3a-3c.}

The deep investigation carried out on the reactivity in MRH of $\mathbf{3 d}-\mathbf{f}$ furnishes the instrument for a comparison with the reactivity of the $(Z)$-hydrazone $(\mathbf{3 a}),{ }^{7 \mathrm{j}}$ the $(Z)$-phenylhydrazone $(\mathbf{3 b})^{7 \mathrm{a}}$ and the (Z)-2,4-dinitrophenylhydrazone $(3 \mathbf{c})^{7 \mathrm{j}}$ of the 3-benzoyl-5-phenyl-1,2,4-oxadiazole: this comparison could allow to evaluate the effects of $\mathrm{CO}-\mathrm{NH}_{2}$ and of acetyl groups on both the nucleophilicity of the $\underline{\mathrm{N}}_{\alpha}$ nitrogen and/or the acidity of the $\mathrm{N}_{\alpha}-\underline{\mathrm{H}}$ proton.

As a matter of fact also 3a-3c rearrange, in dioxane/water, by a general-base-catalyzed mechanism.

As an examination of the Figures 1 and 2 clearly shows, in this case, at $\mathrm{p} S^{+}>6.0$ the acidity of the $\mathrm{N}_{\alpha}-\underline{\mathrm{H}}$ proton seems to be the most important factor in determining the reactivity trend, as indicated by the reactivity ratios under reported and calculated at $\mathrm{p} S^{+}=11.0$ :

$$
k_{3 \mathbf{a}}: k_{\mathbf{3 b}}: k_{\mathbf{3} \mathbf{c}}: k_{\mathbf{3 d}}: k_{\mathbf{3 e}}: k_{\mathbf{3 f}}=1: 256: 10820: 4160: 39670: 28300
$$

this trend well reflecting the above acidity.

\section{A Comparison between the Reactivity of 3d-f and of 7-8. ${ }^{7 \mathrm{e}-\mathrm{f}}$}

Another factor that could be important to consider, in order to rationalize the data obtained, is the side chain structure which in turn affects also the thermodynamic stability of the final products. 
On this point, data now obtained could be compared with those deriving from the reactivity of the 3-phenylureine of the 5-phenyl-1,2,4-oxadiazole (7) ${ }^{7 \mathrm{e}}$ and $\mathrm{N}$-(5-phenyl-1,2,4-oxadiazol-3yl)- $N^{\prime}$-phenylformammidine $(8) .{ }^{7 \mathrm{f}}$ These compounds have a side chain (see Scheme 7 ) of the $-\mathrm{NH}-\mathrm{CO}-\mathrm{N} \underline{\mathrm{H}}-\mathrm{Ph}$ or $-\mathrm{N}=\mathrm{CH}-\mathrm{N} \underline{\mathrm{H}}-\mathrm{Ph}$ types, respectively.<smiles>O=C(Nc1ccccc1)Nc1noc(-c2ccccc2)n1</smiles>

7<smiles>O=C(Nc1nn(-c2ccccc2)c(=O)[nH]1)c1ccccc1</smiles>

9<smiles>C(=N\c1noc(-c2ccccc2)n1)\Nc1ccccc1</smiles>

8<smiles>O=C(Nc1cnn(-c2ccccc2)n1)c1ccccc1</smiles>

10

\section{Scheme 7}

Similarly to $\mathbf{3 e}-\mathbf{f}$, also $7^{7 \mathrm{e}}$ and $\mathbf{8}^{7 \mathrm{f}}$ react via a specific-base-catalyzed mechanism and in Table 2 the relevant $K_{1}, k_{2}$ and $\mathrm{p} K_{a}$ values are collected, while in Table $3 k_{\mathrm{A}, \mathrm{R}}$ at $\mathrm{pS}{ }^{+} 13.0,13.5$ and 14.0 are reported.

Table 3. Apparent rate constants, $k_{\mathrm{A}, \mathrm{R}}$, measured at $\mathrm{pS}^{+} 13.0,13.5$ and 14.0 for the rearrangement of $3 \mathbf{e}-\mathbf{f}, \mathbf{7}$ and $\mathbf{8}$ in $\mathrm{D} / \mathrm{W}(1: 1, \mathrm{v}: \mathrm{v})$.

\begin{tabular}{cccc}
\hline Substrate & $\begin{array}{c}k_{\mathrm{A}, \mathrm{R}}\left(\mathrm{s}^{-1}\right) \\
\mathrm{pS}=13.0\end{array}$ & $\begin{array}{c}k_{\mathrm{A}, \mathrm{R}}\left(\mathrm{s}^{-1}\right) \\
\mathrm{pS}\end{array}$ & $\begin{array}{c}k_{\mathrm{A}, \mathrm{R}}\left(\mathrm{s}^{-1}\right) \\
\mathrm{pS}\end{array}$ \\
\hline 3e & 0.657 & 1.48 & 14.0 \\
3f & 0.593 & 1.27 & 2.44 \\
$7^{\mathrm{a}}$ & $6.15 \cdot 10^{-5}$ & $6.66 \cdot 10^{-5}$ & $6.84 \cdot 10^{-5}$ \\
$\mathbf{8}^{\mathrm{b}}$ & $3.54 \cdot 10^{-4}$ & $8.71 \cdot 10^{-4}$ & $1.62 \cdot 10^{-3}$ \\
\hline
\end{tabular}

${ }^{\mathrm{a}}$ Data from reference $7 \mathrm{e} .{ }^{\mathrm{b}}$ Data from reference $7 \mathrm{f}$.

As can be seen from data in Table 3, at high $\mathrm{pS}^{+}$values (e.g., at $\mathrm{p} S^{+} 13.0$ ), the reactivity order is:

$$
3 f \approx 3 e>8>7
$$


This is different from those expected considering the $\mathrm{p} K_{a}$ values and it keeps constant also at $\mathrm{pS}^{+}=14.5$, when all substrates considered are in their anionic form:

$$
\text { at } \mathrm{p} S^{+}=14.5 \quad k_{\mathbf{3 f}}: k_{\mathbf{3 e}}: k_{\mathbf{8}}: k_{7}=34780: 44350: 32: 1
$$

However these results cannot be explained only considering the nucleophilicity or the acidity of the proton of the $\mathrm{N}_{\alpha}-\underline{\mathrm{H}}$ group. As above indicated the stability of the final product has been found able to affect the reactivity. Probably, the very higher reactivity of $\mathbf{3 e}$, notwithstanding its $\mathrm{p} K_{a}$ value is not much higher than that of $\mathbf{8}$, is due to the different stability of the triazoles formed and this factor can affect the position of the transition state along the reaction coordinates. The kinetic result appears in line with the higher stability (aromaticity) of 2H-1,2,3triazoles in comparison to $1 \mathrm{H}$-1,2,4-triazoles (e.g., compare the relevant $\mathrm{I}_{\mathrm{A}}$ values 109 and 100, respectively). ${ }^{8}$

\section{Rearrangement of 3d-f in Toluene in the Presence of Some Amines.}

To gain information concerning the course of the rearrangement in an apolar solvent we have carried out some kinetic measurements in toluene (in the past we have collected parallel data in benzene, but by some time the laboratory use of this solvent has been strongly discouraged) in the presence of three amines: $n$-butylamine $(\mathrm{BuA})$, piperidine (PIP), and triethylamine (TEA). These are a primary, a secondary, and a tertiary amine, respectively, and show different steric requirements, different basicity, as well as different aptitude to behave as donor or acceptor counterpart in the hydrogen-bond formation. ${ }^{14}$

To allow a comparison between substrates with similar structures, but containing $\mathrm{N}_{\alpha}-\underline{\mathrm{H}}$ with different acidity we have examined the reactivity of the (Z)-semicarbazone $\mathbf{3 d}$, of the $(Z)$ phenylsemicarbazone 3e, and of the (Z)-N-acetylhydrazone $\mathbf{3 f}$ of 3-benzoyl-5-phenyl-1,2,4oxadiazole.

The kinetic measurements have been carried out at $313.1 \mathrm{~K}$ in a large range of amine concentrations ([BuA]: 0.04-0.50 M; [PIP]: 0.01-0.30 M; [TEA]: 0.10-1.00 M). The apparent first-order rate constants $\left(k_{\mathrm{A}, \mathrm{R}}\right)$ are collected in Table 11 of SI.

All of $\mathbf{3 d}-\mathbf{f}$ react with the three amines showing $k_{\mathrm{A}, \mathrm{R}}$ values amine concentration depending, which interestingly well fit different equations as a function of the structure the used amines.

\section{On the Behavior of 3d-f in Toluene with Amines.}

In the instance of the reaction in the presence of butylamine and in contrast in the presence of piperidine and triethylamine the kinetic data at different amine concentrations well fit equations 7 and 8 , respectively

$$
\begin{array}{ll}
k_{\mathrm{A}, \mathrm{R}}=k_{\mathrm{II}}[\mathrm{B}]+k_{\mathrm{III}}[\mathrm{B}]^{2} & \text { eq } 7 \\
k_{\mathrm{A}, \mathrm{R}}=k_{\mathrm{II}}[\mathrm{B}] & \text { eq } 8
\end{array}
$$


as indicated by the results of statistical analysis reported in Table 4.

Table 4. Second and third order rate constants $\left(k_{\mathrm{II}}\right.$ and $\left.k_{\mathrm{III}}\right)$ for the rearrangement of $\mathbf{3 d}-\mathbf{f}$ in toluene and in the presence of amines at $313.1 \mathrm{~K}$.

\begin{tabular}{ccccc}
\hline Substrate & \multicolumn{2}{c}{$\mathbf{B u A}^{\mathrm{a}}$} & PIP $^{\mathrm{b}}$ & TEA $^{\mathrm{c}}$ \\
\hline & $10^{2} k_{\mathrm{II}}\left(\mathrm{mol}^{-1} \mathrm{~L} \mathrm{~s}^{-1}\right)$ & $10^{2} k_{\mathrm{III}}\left(\mathrm{mol}^{-2} \mathrm{~L}^{2} \mathrm{~s}^{-1}\right)$ & $10^{2} k_{\mathrm{II}}\left(\mathrm{mol}^{-1} \mathrm{~L} \mathrm{~s}^{-1}\right)$ & $10^{2} k_{\mathrm{II}}\left(\mathrm{mol}^{-1} \mathrm{~L} \mathrm{~s}^{-1}\right)$ \\
\hline 3d & $0.121 \pm 0.001$ & $1.32 \pm 0.01$ & $2.78 \pm 0.01$ & $0.0192 \pm 0.0001$ \\
3e & $0.227 \pm 0.005$ & $5.57 \pm 0.01$ & $7.48 \pm 0.03$ & $0.0736 \pm 0.0004$ \\
3f & $0.149 \pm 0.001$ & $2.02 \pm 0.00$ & $3.53 \pm 0.01$ & $0.0329 \pm 0.0002$ \\
\hline
\end{tabular}

3d-f: $n=10, r=0.9999 .{ }^{\mathrm{b}}$ 3d: $n=11, r=0.9999 ; \mathbf{3 e}: n=10, r=0.9999 ; \mathbf{3 f}: n=9, r=0.9999$.

'3d-f: $n=10 ; r=0.9999$.

\section{Comments on the Behavior of $3 \mathrm{~d}-\mathrm{f}$ in Toluene with Amines.}

With all of the three substrates and in the presence of all the tested amines no uncatalyzed pathway has been evidenced. This result agrees with some previous observations: also in D/W (that is, in a solvent system much more polar and then eventually more prone to favour the occurrence of a uncatalyzed pathway) the same substrates rearrange only via the base-catalyzed pathway. This is in line with the very low nucleophilicity of the $\mathrm{N}_{\alpha}$ nitrogen atom depending on its conjugation with the adjacent carbon-oxygen double bond: as a consequence once more the examined substrates appear stable in apolar solvents (such as benzene or toluene, see above) as well as in solid state (for years), thus replicating the situation observed with several (Z)-hydrazones ${ }^{7 \mathrm{j}}$ and $(Z)$-arylhydrazones of 3-benzoyl-1,2,4-oxadiazoles. ${ }^{7 \mathrm{~d}}$

Interestingly enough different contributions to base-catalyzed pathways have been observed as a function of the present amine (and its structure).

In the instance of TEA (a tertiary amine) and PIP (a secondary amine) with all the examined substrates (3d-f) only a second-order pathway (i.e., depending on first-order amine concentration) has been observed and this behavior strictly resembles that one evidenced in other MRH [e.g., of the (Z)-4-nitrophenylhydrazone of 3-benzoyl-5-phenyl-1,2,4-oxadiazole ${ }^{15}$ and of the 3-(4-nitrophenyl)ureine of 5-phenyl-1,2,4-oxadiazole ${ }^{7 \mathrm{e}}$ ].

In contrast in the presence of BuA a more complex kinetic expression has been observed: two reaction paths have been observed, the former occurring via a second-order and the latter via a third-order pathway (the first largely prevailing on the other at low amine concentration).

These two results with different amines (TEA and PIP, or BuA) appear of some interest in the light of some our previous kinetic data. The possible interpretations could be related: a) to the ability of aliphatic amines containing hydrogens at nitrogen atom to live as dimers in apolar solvents or b) to an addition of a molecule of amine to the N4-C5 double bond according to a hypothesis of Harsani and coworkers. ${ }^{16}$ 
The present result, also in the light of the results of a DFT study of the course of the reaction in the uncatalyzed pathway, ${ }^{7 j}$ allows to definitively exclude these two hypotheses and clearly support our previous idea of a catalysis-of-catalysis. ${ }^{17}$

As a matter of fact in the presence of BuA $3 \mathbf{d}-\mathbf{f}$ does react via both a second- and a thirdorder pathway (both paths really contributing to the rearrangement).

In the light of some our previous results on the MRH in benzene in the presence of amines ${ }^{17}$ we can suppose that higher orders pathways depend on a catalysis-of-catalysis mechanism. That is, because of the interaction between the $\mathrm{N}_{\alpha}-\underline{\mathrm{H}}$ hydrogen of the side chain with the amine a partial positive charge is created on the nitrogen of amine. If at this nitrogen atom are linked hydrogen atoms, this fact can cause the interaction with a second molecule of amine determining the occurrence of a catalysis-of-catalysis.

In a previous study on $\mathrm{MRH}^{17}$ to confirm the occurrence of general-base-catalysis in apolar solvents and of a catalysis-of-catalysis pathway we carried out a series of kinetics in the presence of mixtures of amines, eg. of BuA and TEA. The apparent first-order rate constants $\left(k_{\mathrm{A}, \mathrm{R}}\right)$ are collected in Table 12 of SI.

In the instance of $\mathbf{3 d - f}$ the kinetic data at different amine concentrations well fit, respectively, eqs 9-11, as indicated by the results of statistical analysis ( $n 39,37$ or 40, r 0.9999).

$$
\begin{aligned}
& 10^{3}\left(k_{\mathrm{A}, \mathrm{R}}\right)_{3 \mathbf{d}}=(0.00 \pm 0.01)+(0.19 \pm 0.01)[\mathrm{TEA}]+(1.15 \pm 0.06)[\mathrm{BuA}]+(13.4 \pm 0.1)[\mathrm{BuA}]^{2}+ \\
& (3.57 \pm 0.06)[\mathrm{BuA}][\mathrm{TEA}]
\end{aligned}
$$

$10^{3}\left(k_{\mathrm{A}, \mathrm{R}}\right)_{3 \mathrm{e}}=(0.005 \pm 0.005)+(0.731 \pm 0.009)[\mathrm{TEA}]+(2.24 \pm 0.05)[\mathrm{BuA}]+(55.7 \pm 0.1)$ $[\mathrm{BuA}]^{2}+(11.8 \pm 0.1)[\mathrm{BuA}][\mathrm{TEA}]$ eq 10

$10^{3}\left(k_{\mathrm{A}, \mathrm{R}}\right)_{3 \mathbf{e}}=(0.00 \pm 0.01)+(0.328 \pm 0.002)[\mathrm{TEA}]+(1.46 \pm 0.08)[\mathrm{BuA}]+(20.3 \pm 0.1)[\mathrm{BuA}]^{2}$ $+(5.69 \pm 0.1)[\mathrm{BuA}][\mathrm{TEA}]$ eq 11

Thus, once more the occurrence of both general-base-catalysis and of catalysis-of-catalysis appears confirmed. As a matter of fact in eqs 9-11 concerning 3d-3f the second-order pathways catalyzed by BuA or by TEA as well as the third-order one catalyzed by BuA are observed: the "now" calculated rate constants very well compare with the values previously calculated (Table $4)$ in the presence of only BuA or TEA amines $(\Delta k<2 \%)$. It must be remarked that all of the present bases contribute to the rearrangement process, as expected for a general-base-catalyzed process. Moreover a third-order pathway, depending on both the two present bases (BuA and TEA), has been observed. ${ }^{17}$ Two comments on this last path can be attached: a) its presence confirms the catalysis-of-catalysis (in such a kind of experimental conditions the TEA molecule assists the hydrogen atom abstraction.; see Scheme 8 for the relevant TS), b) the third-order rate constant calculated is always significantly lower $(75 \pm 4) \%$ than that for the third-order process depending on two molecules of BuA. 


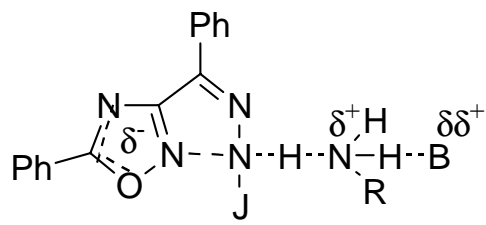

\section{Scheme 8}

As a matter of fact notwithstanding the higher basicity of TEA with respect to $\mathrm{BuA}^{14}$ (which would significantly increase the assistance in the proton abstraction in TS) this factor is overwhelmed by the higher steric hindrance of TEA (a tertiary amine) with respect to BuA (a primary amine). This strongly decreases the possibility of approach to the positively charged hydrogen atom in such a way decreasing the effect on the reactivity.

\section{Conclusions}

The whole of the kinetic results collected on the MRH of $\mathbf{3 d - f}$ in $\mathrm{D} / \mathrm{W}$ and in toluene has pointed out the following points:

a) by studying the MRH of 3d-f in D/W evidence has been collected in favour of a specificbase-catalyzed pathway, the different reactivity of the three substrates examined being essentially related to the different acidity of the hydrogen of the $\mathrm{N}_{\alpha}-\underline{\mathrm{H}}$ system. In contrast no evidence in favour of a uncatalyzed pathway has been collected;

b) by studying the MRH of $\mathbf{3 d - e}$ in toluene evidence has been collected in favour of a generalbase-catalyzed pathway with different contribution of second- and third-order pathways depending on structure of both substrate and amine; again no evidence in favour of a uncatalyzed pathway has been collected;

c) in toluene the third-order-pathway observed has been related to a catalysis-of-catalysis process; as indicated also by results with a couple of amines. The results obtained on this point definitively confirm this hypothesis and show that higher is the acidity of the hydrogen of the $\mathrm{N}_{\alpha}-\underline{\mathrm{H}}$ system, higher is in the TS its interaction with a first molecule of the basic amine and then the breaking of the $\mathrm{N}_{\alpha}-\underline{\mathrm{H}}$ bond can go on. The related higher partial positive charge on the nitrogen of amine increases the "necessity" of assistance from a second molecules of amine: that is, of catalysis-of-catalysis. 


\section{Experimental Section}

\section{Synthesis and Purification of Compounds}

Compounds $\mathbf{3} \mathbf{d}^{18}$ and $\mathbf{4 d},{ }^{18}$ water, ${ }^{19}$ dioxane ${ }^{19}$ and toluene ${ }^{19}$ were prepared and/or purified according to the methods reported. Piperidine, butylamine, and triethylamine were purified by standing over potassium hydroxide $(24 \mathrm{~h})$ and fractionally distilled twice before use.

Compounds $\mathbf{3 e}$ and $\mathbf{3 f}$ were prepared from 3-benzoyl-5-phenyl-1,2,4-oxadiazole and phenylsemicarbazide hydrochloride or acetylhydrazine hydrochloride, respectively, in ethanol following a previous procedure. ${ }^{18}$ Purification was achieved by chromatography [silica gel: cycloexane/ethylacetate (20/1)] and crystallization from ethanol.

Compound $\mathbf{3 e}$ was rearranged into the relevant triazole $4 \mathbf{e}$ by standing in ethanol in the presence of aqueous $\mathrm{KOH}(10 \%)$ at room temperature until disappearance of the starting product (tlc analysis). It was purified by crystallization from ethanol.

The treatment of compound $\mathbf{3 f}$ with aqueous $\mathrm{KOH}(10 \%)$ in ethanol, gives as final product the 4benzoylamino-5-phenyl- $2 \mathrm{H}-1,2,3$-triazole $(\mathbf{4 a})^{7 \mathrm{j}}$ by fast hydrolysis of the firstly formed 2-acetyl4-benzoylamino-5-phenyl-2H-1,2,3-triazole (4f).

Physical data of 3e. Colourless solid, mp $172^{\circ} \mathrm{C}$; $v$ (nujol) $1705,1732,3246,3371 \mathrm{~cm}^{-1} ;{ }^{1} \mathrm{H}$ NMR $\left(250 \mathrm{MHz}, \mathrm{CDCl}_{3}\right) \delta 11.34(1 \mathrm{H}, \mathrm{s}, \mathrm{NH}), 8.38(1 \mathrm{H}, \mathrm{s}, \mathrm{NH}), 8.27-8.23(2 \mathrm{H}, \mathrm{dd}, \mathrm{Ar}, \mathrm{J}=1.3$ and 4.7 Hz), 7.87-7.83 (2H, m, Ar), 7.72-7.50 (7H, m, Ar), 7.40-7.37 (2H, m, Ar), 7.15-7.09 $(2 \mathrm{H}, \mathrm{m}, \mathrm{Ar}) ;{ }^{13} \mathrm{C}$ NMR $\left(250 \mathrm{MHz}, \mathrm{CDCl}_{3}\right) \delta 175.67,163.40,152.15,137.65,135.21,133.77$, $131.58,129.61,129.35,129.00,128.70,128.56,128.37,123.65,122.86,119.58$. MS m/z 383 $\left(\mathrm{M}^{+}, 3\right) ; 264$ (78); 236 (71); 133 (43); 119 (93); 105 (100); 91 (92); 77 (96); 64 (87); 51 (75). HRMS calcd for $\mathrm{C}_{22} \mathrm{H}_{17} \mathrm{~N}_{5} \mathrm{O}_{2}: 383.1382$, found: 383.1384 .

Physical data of 3f. Colourless solid, mp $135^{\circ} \mathrm{C}$, v (nujol) $1678,1701,3240 \mathrm{~cm}^{-1} ;{ }^{1} \mathrm{H}$ NMR (300 $\left.\mathrm{MHz}, \mathrm{CDCl}_{3}\right) \delta 11.69(1 \mathrm{H}, \mathrm{s}, \mathrm{NH}), 8.26-8.23(2 \mathrm{H}, \mathrm{dd}, \mathrm{Ar}, \mathrm{J}=1.5$ and $4.8 \mathrm{~Hz}), 7.90-7.86(2 \mathrm{H}$, $\mathrm{m}, \mathrm{Ar}), 7.70-7.59$ (3H, m, Ar), 7.50-7.47 (m; 3H, Ar, 1H, NH), $2.48(3 \mathrm{H}, \mathrm{s}, \mathrm{Me}) ;{ }^{13} \mathrm{C}$ NMR $(300$ $\left.\mathrm{MHz}, \mathrm{CDCl}_{3}\right) \delta 176.88,175.04 ; 163.99 ; 136.32 ; 134.88 ; 134.27 ; 130.75 ; 130.45 ; 129.66$; 129.38; 123.96; 21.38. MS m/z 306(M $\left.\mathrm{M}^{+}, 12\right) ; 236$ (14); 105 (100); 77 (28); 43 (10). HRMS calcd for $\mathrm{C}_{17} \mathrm{H}_{14} \mathrm{~N}_{4} \mathrm{O}_{2}: 306.1114$, found: 306.1117 .

Physical data of 4e. Colourless solid, mp $205^{\circ} \mathrm{C}$; $\mathrm{v}$ (nujol) 1686, 1716.5, 3192, $3140 \mathrm{~cm}^{-1} ;{ }^{1} \mathrm{H}$ NMR $\left(250 \mathrm{MHz}, \mathrm{CDCl}_{3}\right) \delta 10.65(1 \mathrm{H}, \mathrm{s}, \mathrm{NH}), 9.32(1 \mathrm{H}, \mathrm{s}, \mathrm{NH}), 8.30-8.26(2 \mathrm{H}, \mathrm{m}, \mathrm{Ar}), 7.92-$ $7.74(6 \mathrm{H}, \mathrm{m}, \mathrm{Ar}), 7.49-7.45$ (4H, m, Ar), 7.41-7.34 (2H, m, Ar), 7.14-7.09 (1H, m, Ar); ${ }^{13} \mathrm{C}$ NMR $\left(250 \mathrm{MHz}, \mathrm{CDCl}_{3}\right) \delta 176.08,167.89,151.83,137.50,136.86,133.20,130.84,129.87$, $129.19,129.00,128.82,128.39,128.32,123.92,123.73,120.12$. MS m/z $383\left(\mathrm{M}^{+}, 3\right) ; 264(10)$; 137 (12); 119 (12); 105 (100); 93 (92); 77 (54); 69 (93); 57 (20); 41 (25). HRMS calcd for $\mathrm{C}_{22} \mathrm{H}_{17} \mathrm{~N}_{5} \mathrm{O}_{2}: 383.1382$, found: 383.1385 . 


\section{$\mathrm{pS}^{+}$Scale Definition and Kinetic Measurements.}

The operational proton-concentration scale used $\left(\mathrm{pS}^{+}\right)^{7 \mathrm{a}, 20 \mathrm{a}}$ was established in aqueous dioxane by employing the $\mathrm{p} K_{\mathrm{a}}$ values of acids determined by interpolation from reported data. ${ }^{20 \mathrm{~b}}$ The meter reading after calibration against buffers required a correction of only +0.16 .

The kinetics were followed spectrophotometrically as previous described ${ }^{7}$ by measuring the disappearance of $\mathbf{3 e}-\mathbf{f}$ at the wavelengths of their absorption maxima, where the absorptions of the rearranged triazoles were minimal. The solutions at infinity time were checked and they well fitted the complete formation of the expected triazoles.

A Varian Cary 1E spectrophotometer equipped with the rapid kinetic accessory SFA-11 was used at high $\mathrm{pS}^{+}$values for the rearrangement of $\mathbf{3 d}-\mathbf{f}$ in dioxane/water.

\section{Acknowledgements}

We thank for financial support MIUR (Roma) (PRIN) and the Universities of Bologna and Palermo.

\section{References}

1. On the use of heterocycles as masked functionalities, see: (a) Dondoni, A. In Modern Synthetic Methods; Scheffold, R., Ed.; Verlag Helvetica Chimica Acta: Basel, Switzerland, 1992, 377. (b) Dondoni, A.; Marra, A. In Preparative Carbohydrates Chemistry; Hanessian, S., Ed.; M. Dekker: New York, 1997; Chapter 9, 173. (c) Patai, S.; Rappoport, Z., Eds. The Chemistry of Functional Groups; Wiley: New York, a series of monographs edited from 1992 to 2008. (d) Recently, Chemical Reviews dedicated an issue to different aspects of heterocyclic chemistry (Katritzky, A. R. Ed. Chem. Rev. 2004, 104, 2125), well pointing out its role in organic synthesis.

2. (a) Pathak, A. K.; Pathak, V.; Seitz, W. J.; Reynolds, R. C. J. Med. Chem. 2004, 47, 273. (b) Andreani, A.; Granaiola, M.; Leoni, A.; Locatelli, A.; Morigi, R.; Rambaldi, M.; Garaliene, V.; Farruggia, G.; Masotti, L. Bioorg. Med. Chem. 2004, 12, 1121. (c) Andreani, A.; Granaiola, M.; Leoni, A.; Locatelli, A.; Morigi, R.; Rambaldi, M.; Recanatini, M.; Lenaz, G.; Fato, R.; Bergamini, C. Bioorg. Med. Chem. 2004, 12, 5525. (d) Budriesi, R.; Cosimelli, B.; Ioan, P.; Lanza, C. Z.; Spinelli, D.; Chiarini, A. J. Med. Chem. 2002, 45, 3475. (e) Budriesi, R.; Carosati, E.; Chiarini, A.; Cosimelli, B.; Cruciani, G.; Ioan, P.; Spinelli, D.; Spisani, R. J. Med. Chem. 2005, 48, 2445. (f) Almajan, G. L.; Innocenti, A.; Puccetti, L.; Manole, G.; Barbuceanu, I. S.; Scozzafava, A.; Supuran, C. T. Bioorg. Med. Chem. Lett. 2005, 15, 2347. (g) Laughlin, S. K.; Clark, M. P.; Djung, J. F.; Golebiowski, A.; Brugel, T.A.; Sabat, M.; Bookland, R. G.; Laufersweiler, M. J.; VanRens, J. C.; Townes, J. A. Bioorg. Med. Chem. Lett. 2005, 15, 2399. (h) Vullo, D.; Innocenti, A.; Nishimori, I.; Pastorek, J.; Scozzafava, A.; 
Pastorekova, S.; Supuran, C. T. Bioorg. Med. Chem. Lett. 2005, 15, 963. (i) Compton, D. R.; Carlson, K. E.; Katzenellenbogen, J. A. Bioorg. Med. Chem. Lett. 2004, 14, 5681. (j) LeungToung, R.; Wodzinska, J.; Li, W.; Lowrie, J.; Kukreja, R.; Desilets, D.; Karimian, K.; Tam, T. F. Bioorg. Med. Chem. 2003, 11, 5529. “(k) Viale, M.; Cordazzo, C.; Cosimelli, B.; de Totero, D.; Castagnola, P.; Aiello, C.; Severi, E.; Petrillo, G.; Cinfriglia, Spinelli. D. J. Med. Chem. 2009, 52, 259. (1) Wu, C.-C.; Chang, C.-F.; Bai, S. J. Thin Solid Films 2005, 479, 245. (m) Lin, I. J. B.; Vasam, C. S. J. Organomet. Chem. 2005, 690, 3498. (n) Shimada, S.; Hanai, T.; Yamamoto, O.; Saitoh, H. Thin Solid Films 2005, 471, 128. (o) Noor, E. A. Corrosion Science 2005, 47, 33. (p) Mashraqui, S. H.; Kenny, R. S.; Ghadigaonkar, S. G.; Krishnan, A.; Bhattacharya, M.; Das, P. K. Optical Materials 2004, 27, 257.

3. (a) Trost, B. M.; Fleming, I. Eds., Comprehensive Organic Synthesis, Pergamon, 1991. (b) Katritzky, A. R.; Rees, C. W. Eds., Comprehensive Heterocyclic Chemistry I, Pergamon; Katritzky, A. R.; Rees, C. W.; Scriven, E. F. V. Eds., Comprehensive Heterocyclic Chemistry II, Pergamon; Katrizky, A. R.; Ramsden, C. A.; Scriven, E. F. V.; Taylor, R. J. K. Eds., Comprehensive Heterocyclic Chemistry III, Elsevier.

4. (a) Ruck-Brown, K.; Martin, T.; Miculàs, M. Chemistry A European Journal 1999, 3, 1028.

(b) Exner, K.; Fischer, G.; Lugan, M.; Fritz, H.; Hunkler, D.; Keller, M.; Knotthe, L.; Prinzbach, H. Eur. J. Org. Chem. 2000, 787. (c) Csende, F.; Stager, G. Heterocycles 2000, 6, 1379. (d) Kitamura, M.; Narasaka, K. Chemical Record 2 2002, 4, 268. (e) Lanker, P.; Armbrust, H.; Eckardt, T.; Magull, J. Chemistry A European Journal 2002, 6, 1443. (f) Abele, E.; Lukevics, E. Heterocycles 2002, 2, 361. (g) Bouillon, J. P.; Capperucci, A.; Portella, C.; Degl'Innocenti, A. Tetrahedron Letters 2004, 45, 87. (h) Brandi, A.; Chicchi, S.; Corsero, F. M.; Goti, A. Chem. Rev. 2003, 103, 1213. (i) Giacomelli, G.; Porcheddu, A, De Luca, L. Current Org. Chem. 2004, 15, 1497. (j) Degl'Innocenti, A.; Capperucci, A.; Castagnoli, G.; Malesi, I. Synlett 2005, 13, 1965. (k) Palacios, F.; Aparicio, D; Lopez, Y.; De Los Santos, J. M.; Ezpeleta, J. M. Tetrahedron 2006, 62, 1095. (1) Ila, H.; Baron, O.; Wagner, A. J.; Knochel, P. Chem. Comm. 2006, 583. (m) De Figuereido, R. H.; Frohlich, R.; Christmann, M. J. Org. Chem. 2006, 71, 4147.

5. (a) Van der Plas, H. C. Adv. Heterocycl. Chem. 1999, 74, 1. (b) Werman, K.; Walther, M.; Gunther, W.; Gorls, H.; Anders, E. Tetrahedron 2005, 61, 673. (c) Buscemi, S.; Pace, A.; Palumbo Piccionello, A.; Pibiri, I.; Vivona, N.; Giorgi, G.; Mazzanti, A.; Spinelli, D. J. Org. Chem. 2006, 71, 8106.

6. (a) Boulton, A. J.; Katritzky, A. R.; Majid-Hamid, A. J. Chem. Soc., C 1967, 2005. (b) Boulton, A. J. Lectures in Heterocyclic Chemistry; Hetero Corporation: Provo, UT, 1973. (c) Katritzky, A. R.; Gordev, M. F. Heterocycles 1993, 35, 483. (d) van der Plas, H. C.; In Ring Transformation of Heterocycles; Academic Press: London, 1973; vols. 1 and 2. (e) L'abbé, G. J. Heterocycl. Chem. 1984, 21, 627. (f) Ruccia, M.; Vivona, N.; Spinelli, D. Adv. Heterocycl. Chem. 1981, 29, 141. (g) Vivona, N.; Buscemi, S.; Frenna, V.; Cusmano, G. Adv. Heterocycl. Chem. 1993, 56, 49. 
7. (a) Spinelli, D.; Corrao, A.; Frenna, V.; Vivona, N.; Ruccia, M.; Cusmano, G. J. Heterocycl. Chem. 1976, 13, 357. (b) Spinelli, D.; Frenna, V.; Corrao, A.; Vivona, N. J. Chem. Soc., Perkin Trans. II 1978, 19. (c) Frenna, V.; Vivona, N.; Consiglio, G.; Corrao, A.; Spinelli D. J. Chem. Soc., Perkin Trans. II 1981, 1325. (d) Frenna, V.; Vivona, N.; Corrao, A.; Consiglio, G.; Spinelli, D. J. Chem. Res. Synop 1981, 308; Miniprint 3550. (e) Frenna, V.; Spinelli, D.; Consiglio, G. J. Chem. Soc., Perkin Trans. 2 1990, 1289. (f). Frenna, V.; Vivona, N.; Consiglio, G.; Spinelli, D.; Mezzina, E. J. Chem. Soc., Perkin Trans. 2 1993, 1339. (g) Cosimelli, B.; Guernelli, S.; Spinelli, D.; Buscemi, S.; Frenna, V.; Macaluso, G. J. Org. Chem. 2001, 66, 6124. (h) Cosimelli, B.; Frenna, V.; Guernelli, S.; Lanza, C. Z.; Macaluso, G.; Petrillo, G.; Spinelli, D. J. Org. Chem. 2002, 67, 8010. (i) D’Anna, F.; Frenna, V.; Macaluso, G.; Morganti, S.; Nitti, P.; Pace, V.; Spinelli, D.; Spisani, R. J. Org. Chem. 2004, 69, 8718. (j) Bottoni, A.; Frenna, V.; Lanza, C. Z.; Macaluso, G.; Spinelli, D. J. Phys. Chem. A 2004, 108, 1731. (k) D’Anna, F.; Frenna, V.; Macaluso, G.; Marullo, S.; Morganti, S.; Pace, V.; Spinelli, D.; Spisani, R.; Tavani, C. J. Org. Chem. 2006, 71, 5616.

8. (a) Bird, C. W. Tetrahedron 1985, 41, 1409. (b) Bird, C. W. Tetrahedron 1992, 48, 335. (c) Bean, P. G. J. Org. Chem. 1998, 63, 2497. (d) Katritzky, A. R.; Jug, K.; Oniciu, D. C. Chem. Rev., 2001, 101, 1421. (d) Katritzky, A. R.; Barczynsky, P.; Musumarra, G.; Pisano, D.; Szafran, M. J. Am. Chem. Soc. 1989, 111, 7.

9. (a) Laidler, K. J. Chemical Kinetics; McGraw-Hill: London, 1965, 450. (b) Hammett, L. P. Physical Organic Chemistry, $2^{\text {nd }}$ ed.; McGraw-Hill: New York, 1970; Chapter 10. (c) Laidler, K. J.; Bunting, P. S. The Chemical Kinetics of Enzyme Action; Clarendon Press: Oxford, 1973, 60. (d) Ritchie, C. D. The Physical Organic Chemistry, The Fundamental Concepts; M. Dekker: New York, 1975; Chapter 7. (e) Exner, O. Correlation Analysis of Chemical Data; Plenum Press: New York and London, 1988; Chapter 7.4. (f) Williams, A. Concerted Organic and Bioorganic Mechanism; CRC Press: Boca Baton, FL, 2000. (g) Carey, F. A.; Sundberg, R. J. Advanced Organic Chemistry; Kluwer Academic/Plenum Publishers: New York, 2000; Chapter 4.8. (h) Williams, A. Free Energy Relationships in Organic and Bio-organic Chemistry; RCS Cambridge, UK, 2003. (k) Anslyn, E. V.; Doughherty, D. A. Modern Physical Organic Chemistry, University Science Books, Sausalito, Ca., USA, 2006. (1) Skrabal, A. Z. Elektrochem. 1927, 33, 322.

10. For the occurrence of the specific-base-catalysis ${ }^{9}$ it is required that the involved $\mathrm{N}_{\alpha}-\underline{\mathrm{H}}$ proton be more acidic than water protons, see after eq.s 1 and 2.

11. Frisch, M. J.; Trucks, G. W.; Schlegel, H. B.; Scuseria, G. E.; Robb, M. A.; Cheeseman, J. R.; Zakrzewski, V. G.; Montgomery, J. A., Jr.; Stratman, R. E.; Burant, J. C.; Dapprich, S.; Millam, J. M.; Daniels, A. D.; Kudin, K. N.; Strain, M. C.; Farkas, O.; Tomasi, J.; Barone, V.; Cossi, M.; Cammi, R.; Mennucci, B.; Pomelli, C.; Adamo, C.; Clifford, S.; Ochterski, J.; Petersson, G. A.; Ayala, P. Y.; Cui, Q.; Morokuma, K.; Malick, D. K.; Rabuck, A. D.; Raghavachari, K.; Foresman, J. B.; Cioslowski, J.; Ortiz, J. V.; Stefanov, B. B.; Liu, G.; Liashenko, A.; Piskorz, P.; Komaromi, I.; Gomperts, R.; Martin, R. L.; Fox, D. J.; Keith, T.; Al-Laham, M. A.; Peng, C. Y.; Nanayakkara, A.; Gonzalez, C.; Challacombe, M.; Gill, P. M. 
W.; Jhonson, B. G.; Chen, W.; Wong, M. W.; Andres, J. L.; Head-Gordon, M.; Replogle, E. S.; Pople, J. A. Gaussian 98, revision A.6, Gaussian, Inc.: Pittsburgh, PA, 1998. (b) Godbout, N.; Salahub, D. R.; Andzelm, J.; Wimmer, E. Can. J. Chem. 1992, 70, 560. Unichem Dgauss, version 2.3.1, 1994, Cray Research, Inc.

12. Klamnt, A. J. Phys. Chem. 1995, 99, 2224; 1996, 100, 3349.

13. In the range of $\mathrm{pS}^{+} 5-11$ a linear plot has been observed for all of the three substrates examined: slopes quite near to unity $(0.93,0.94$, and 0.95 , respectively) have been calculated in good agreement with the occurrence of base-catalysis in a water-like solvent.

14. Their basicity (ion-pair formation with 2,4-dinitrophenol) has been measured in benzene: $\left(K_{\mathrm{B}}\right)_{\mathrm{BuA}}$ : 110, $\left(K_{\mathrm{B}}\right)_{\mathrm{PIP}}: 4490$, and $\left(K_{\mathrm{B}}\right)_{\mathrm{TEA}}: 2700$. Frenna, V.; Vivona, N.; Consiglio, G.; Spinelli, D. J. Chem. Soc., Perkin Trans. II 1985, 1865.

15. Frenna, V.; Vivona, N.; Spinelli, D.; Consiglio, G. J. Heterocyclic Chem. 1981, 18, 723.

16. Harsanyi, K. J. Heterocyclic Chem. 1973, 10, 957.

17. Frenna, V.; Vivona, N.; Caronia, A.; Consiglio, G.; Spinelli, D. J. Chem. Soc., Perkin Trans II 1983, 1203.

18. Ruccia, M.; Spinelli, D. Gazz. Chim. Ital. 1959, 89, 1654.

19. Weissberger, A. Technique of Organic Chemistry, $2^{\text {nd }}$ ed.; Interscience Publ.; New York, 1955; vol. 7, pp 315-320.

20. (a) Bates, R. G.; In Solute-Solvent Interactions; Coetze, J. F.; Ritchie, C. D. Eds.; Marcel Dekker; New York, 1969; p 46. (b) Harned, H. S.; Owen, B. B. The Physical Chemistry of Electrolytic Solution, $3^{\text {rd }}$ ed.; ACS Monograph No 137; Reinhold; New York, 1970, pp 716, 755. 